\title{
Trends in ophthalmology resident surgical experience from 2009 to 2015
}

This article was published in the following Dove Press journal:

Clinical Ophthalmology

28 June 2016

Number of times this article has been viewed

\author{
Nisha Chadha ${ }^{1,2}$ \\ ji Liu' \\ Jessica S Maslin' \\ Christopher C Teng' \\ 'Department of Ophthalmology and \\ Visual Science, Yale University School \\ of Medicine, New Haven, CT, USA; \\ ${ }^{2}$ Department of Ophthalmology, Icahn \\ School of Medicine at Mount Sinai, \\ New York, NY, USA
}

Background: Resident procedure minimums have been established in surgical training programs to ensure adequate training experience. However, achievement of these minimums may fluctuate Review of resident experience is essential for maintaining successful training curricula.

Objective: To evaluate trends in ophthalmology resident surgical experience from 2009 to 2015.

Methods: This was a database study reviewing Accreditation Council for Graduate Medical Education ophthalmology resident surgical case logs. Case logs from 2,797 US ophthalmology residents were reviewed for trends in average surgical cases performed by residents as primary surgeon in the area of cataract, cornea, retina, glaucoma, pediatrics, plastics, and trauma from 2009 to 2015.

Results: Significant trends in resident surgical experience were demonstrated in the areas of cataract, retina, and glaucoma, while experience in cornea, pediatrics, plastics, and trauma remained stable. These trends included an increase in average cases of phacoemulsification cataract surgery from 143.8 to 173.6 , vitreous tap/inject procedures from 31.3 to 93.1 , and glaucoma shunt surgery from 4.5 to 6.7 , with a decline in average cases of nonphacoemulsification cataract surgery from 3.8 to 2.2 , retinal photocoagulation from 59.6 to 45.5 , and filtering surgery from 6 to 4.5 .

Conclusion: Trends in ophthalmology surgical experience in cataract, retina, and glaucoma paralleled new surgical or therapeutic developments as well as practice pattern shifts in these fields. Educators should be cognizant of the impact of such trends on resident experience and determine if curricular adjustments should be made to maintain comprehensive education of physicians-in-training.

Keywords: ophthalmology education, resident education, surgical education

\section{Introduction}

Ophthalmology has experienced many recent therapeutic breakthroughs and innovations that have influenced approach to disease management, surgical technique, and practice patterns. Since the introduction of phacoemulsification in 1967, cataract surgery has continued to evolve, with smaller incision procedures, development of premium intraocular lenses and laser-assisted surgery. ${ }^{1-3}$ In the field of retina, antivascular endothelial growth factor (anti-VEGF) intravitreal injections have revolutionized treatment of macular edema and choroidal neovascularization. ${ }^{4-6}$ The field of glaucoma has experienced a new wave of therapeutic tools, with the development of microinvasive glaucoma surgery such as trabeculectomy ab interno and trabecular meshwork bypass shunts. ${ }^{7,8}$ In the cornea subspecialty, advances in partial thickness corneal transplant surgeries have transformed the field. ${ }^{9}$ 
All of these unique therapies continue to advance ophthalmology and offer hope for improved visual rehabilitation in various conditions. While expanding the array of therapeutic tools, these advances also challenge medical educators with the task of training residents with these new skills and in traditional management approaches. Given these recent advances, many studies have evaluated shifts in practice patterns among practicing ophthalmologists. ${ }^{10-13}$ However, few studies have evaluated shifts in the experience of ophthalmology residents. ${ }^{14}$ The Accreditation Council for Graduate Medical Education (ACGME) is a nonprofit organization whose mission is to support high-quality resident and fellow education through accreditation of residency training programs. It collects resident case logs annually as part of maintenance of accreditation. In this study, we evaluate trends in resident surgical experience with core ophthalmic procedures from 2009 to 2015 by reviewing the ACGME resident case logs.

\section{Methods}

ACGME resident surgical case logs on cataract, cornea, retina, glaucoma, pediatrics, plastics, and trauma procedures published from 2009 to 2015 were analyzed for year-to-year trends in the average number of cases performed as primary surgeon. ${ }^{15}$ The Yale University Institutional Review Board (IRB)/Ethics Committee ruled that IRB approval was not required for this study as it did not involve human subjects.

\section{Results}

From 2009 to 2015, the average number of residency programs per year was 166.3 , and the total number of residents was 2,797 for all 6 years. During this 6-year period, the average number of "phacoemulsification" cases performed by residents as primary surgeon steadily increased from 143.8 to 173.6. Concurrently, the average number of "nonphacoemulsification/extracapsular cataract extraction" (ECCE) cases decreased from 3.8 to 2.2. Average number of primary anterior vitrectomy cases also declined from 3 to 1.8 over the same 6 -year period (Table 1 ).

For cornea, the average number of "keratoplasty" and "other cornea" procedures remained relatively stable, ranging from 2.1 to 2.5 and 4 to 4.5 cases, respectively, over the 6-year period (Table 1).

For retinal procedures, average "vitreous tap/inject" cases increased from 31.3 in 2009-2010 to 93.1 in 2014-2015. Concurrently, average laser panretinal photocoagulation (PRP) decreased from 59.6 to 45.5 cases and focal lasers decreased from 15.7 to 6.8 cases. The data for focal laser were available only from 2011 onward. Posterior vitrectomy cases remained stable, ranging from 4.8 to 5.4 from 2009 to 2015 (Table 1).

For glaucoma, from 2009 to 2015, average "filtering procedures" decreased from 6 to 4.5 cases, while average "shunting procedures" with glaucoma drainage implants (GDIs) increased from 4.5 to 6.7 cases (Table 1).

Pediatric, plastics, and trauma cases performed by residents as primary surgeon remained relatively stable from 2009 to 2015. Average number of extraocular muscle surgery cases remained steady, ranging from 24.4 to 26.6 over the 6-year period. Ptosis repair and blepharoplasty/reconstruction cases slightly increased, ranging from 6.1 to 6.7 and 9.1 to 11.2 , respectively. Entropion/ectropion cases remained stable,

Table I ACGME ophthalmology resident average procedures

\begin{tabular}{|c|c|c|c|c|c|c|}
\hline Procedures & 2009-2010 & $2010-2011$ & $20 I I-2012$ & $2012-2013$ & $2013-2014$ & $2014-2015$ \\
\hline Number of residency programs & 115 & 117 & 117 & 117 & 116 & 116 \\
\hline Number of residents & 447 & 470 & 474 & 475 & 463 & 468 \\
\hline Phacoemulsification & 143.8 & 148.2 & 149.8 & 155.2 & 161.4 & 173.6 \\
\hline Nonphacoemulsification ECCE & 3.8 & 3.6 & 3 & 2.5 & 2.3 & 2.2 \\
\hline Anterior vitrectomy & 3 & 2.7 & 2.7 & 2 & 2 & 1.8 \\
\hline Keratoplasty & 2.3 & 2.4 & 2.3 & 2.1 & 2.5 & 2.5 \\
\hline Other cornea & 4 & 4.1 & 4.5 & 4.4 & 4.2 & 4.0 \\
\hline Vitreous tap/inject & 31.3 & 45.7 & 64.7 & 72.6 & 85 & 93.1 \\
\hline Laser photocoagulation & 59.6 & 64.6 & 48.7 & 52.1 & 50 & 45.5 \\
\hline Focal laser photocoagulation & $N / A$ & $N / A$ & 15.7 & 13 & 10.3 & 6.8 \\
\hline Posterior vitrectomy & 5.1 & 5.4 & 5.3 & 5.2 & 4.8 & 5.0 \\
\hline Filtering procedures & 6 & 4.9 & 4.5 & 4.2 & 4.2 & 4.5 \\
\hline Shunting procedures & 4.5 & 5.1 & 5.7 & 6 & 6.8 & 6.7 \\
\hline Extraocular muscle surgery & 24.8 & 25.5 & 25.7 & 26.6 & 24.4 & 25.0 \\
\hline Ptosis repair & 6.1 & 6.2 & 6.6 & 6.5 & 6.5 & 6.7 \\
\hline Blepharoplasty/reconstruction & 9.1 & 9.9 & 10.4 & 10.2 & 10.2 & II.2 \\
\hline Entropion/ectropion repair & 5.1 & 5.2 & 5 & 4.7 & 4.7 & 4.9 \\
\hline Globe rupture & 7.2 & 7.2 & 7.3 & 7.5 & 7.4 & 7.6 \\
\hline
\end{tabular}

Abbreviations: ACGME, Accreditation Council for Graduate Medical Education; ECCE, extracapsular cataract extraction; NA, not available. 
ranging from 4.7 to 5.2 cases. Globe rupture repair ranged from 7.2 to 7.6 cases over this 6 -year period (Table 1).

\section{Discussion}

A review of the ACGME ophthalmology resident case logs from 2009 to 2015 revealed significant trends in the areas of cataract, retina, and glaucoma procedures, while cornea, pediatric, plastic, and trauma procedure experience remained relatively stable.

In the category of cataract surgery, resident primary cases in phacoemulsification steadily increased while ECCE cases declined. Since the advent of phacoemulsification, ECCE has largely been reserved for mature or hypermature cataracts. The trend in resident experience with ECCE is likely a reflection of practicing ophthalmologists' shift toward phacoemulsification for standard cataract surgery. This trend suggests that over the next few years, residents may no longer have ECCE experience during their training. It raises the question of whether ECCE case minimums should be established to equip residents with an alternate method of cataract extraction in cases not suitable for phacoemulsification. This trend suggests that educators may need to provide more didactic education on this technique and highlight important steps during other procedures with related surgical maneuvers. Additionally, since ECCE is commonly practiced in other nations, where patients may present with more advanced cataracts, it may be advantageous for US residents to be familiar with this approach, which may prepare them better for experiences in international ophthalmology.

The field of retina has undergone tremendous advances over the past decade, with the development of intravitreal anti-VEGF therapies. Significant changes in resident retina procedural experience were identified from 2009 to 2015. Most notably, primary resident vitreous tap/inject procedures almost tripled over this 6-year period, while laser PRP and focal laser experience slowly declined. Although average PRP experience demonstrated a declining trend, the average number of cases remained relatively high at 45.5 in the 2014-2015 academic year. Therefore, PRP does not seem to be a skill at risk of becoming lost to future residents. However, the number of focal laser cases was quite low and on a declining trend, which could make it absent from residency curricula in the future.

Resident glaucoma surgery also demonstrated significant changes from 2009 to 2015 . Filtering surgery experience generally declined, while GDI surgery increased. In 2009-2010, residents performed a greater number of filtering surgeries than GDI surgeries. However, by 2014-2015, this trend had reversed. This shift in practice pattern has been demonstrated in American Glaucoma Society surveys of practicing glaucoma specialists as well as Medicare claims data, and has likely influenced trainee surgical experience. ${ }^{12-14}$ The decline in filtering surgery experience is concerning considering it is a core surgical management procedure in glaucoma. Glaucoma educators may need to find a way to maintain trabeculectomy training in the setting of decreasing surgical volume. Construction of partial thickness scleral flaps for GDI tube coverage may be a means of teaching flap creation for trabeculectomy.

While corneal surgery has experienced many advances in the area of partial thickness graft surgery, it does not seem to have impacted resident cornea surgery experience yet. Resident cornea procedure average values remained relatively stable. Because cornea procedures were categorized broadly as "keratoplasty" and "other cornea" procedures, it is difficult to analyze resident cornea experience in further detail.

Resident experience with extraocular muscle surgery also remained stable from 2009 to 2015. Botox injection for strabismus correction emerged as a new therapeutic option, but does not appear to have affected resident surgical experience with traditional muscle surgery and is not currently part of the case logs. ${ }^{16}$ Likewise, in plastics, while many new technologies continue to emerge, resident case numbers with ptosis repair, blepharoplasty, and entropion/ectropion repair have remained stable. Lastly, resident trauma experience with globe rupture repair remained relatively stable from 2009 to 2015.

\section{Conclusion}

In reviewing the ACGME case logs of ophthalmology residents over the past 6 years, significant changes in surgical experience in the area of cataract, retina, and glaucoma were identified. The trends in these subspecialty areas correspond to the development of new techniques or therapies in these fields. Some of these trends also parallel practice pattern shifts by practicing ophthalmologists. These findings highlight a need for educators to be aware of how such shifts can influence ophthalmology residents' experience and education. They also suggest that required procedure minimums and resident achievement of these minimums should be periodically reevaluated as new technologies emerge, to help preserve training in core skills as well as remain current with new advances. Finally, educators may need to become innovative in teaching surgical technique of less common procedures.

\section{Acknowledgment}

This work is supported in part by an unrestricted departmental grant from Research to Prevent Blindness (RPB), Inc. 


\section{Disclosure}

The authors report no conflicts of interest in this work.

\section{References}

1. Kelman CD. Phaco-emulsification and aspiration. A new technique of cataract removal. A preliminary report. Am J Ophthalmol. 1967; 64:23-35.

2. De Vries N, Nuijts RM. Multifocal intraocular lenses in cataract surgery: literature review of benefits and side effects. J Cataract Refract Surg. 2013;39:268-278.

3. Nagy Z, Takacs A, Filkorn T, et al. Initial clinical evaluation of an intraocular femtosecond laser in cataract surgery. J Refract Surg. 2009; 25:1053-1060.

4. Rosenfeld PJ, Brown DM, Heier JS, et al. MARINA Study Group. Ranibizumab for neovascular age-related macular degeneration. $N$ Engl J Med. 2006;355:1419-1431.

5. Campochiaro PA, Heier JS, Feiner L, et al. BRAVO Investigators. Ranibizumab for macular edema following branch retinal vein occlusion: six-month primary end point results of a phase III study. Ophthalmology. 2010;117:1102-1112.

6. Brown DM, Campochiaro PA, Singh RP, et al. CRUISE Investigators. Ranibizumab for macular edema following central retinal vein occlusion: six-month primary end point results of a phase III study. Ophthalmology. 2010;117:1124-1133.

7. Minckler DS, Baerveldt G, Alfaro MR, et al. Clinical results with the Trabectome ${ }^{\mathrm{TM}}$ for treatment of open-angle glaucoma. Ophthalmology. 2005;112:962-967.
8. Spiegel D, Wetzel W, Haffner DS, et al. Initial clinical experience with the trabecular micro-bypass stent in patients with glaucoma. Adv Ther. 2007;24:161-170.

9. Ple-Plakon PA, Shtein RM. Trends in corneal transplantation: indications and techniques. Curr Opin Ophthalmol. 2014;25:300-305.

10. Leaming DV. Practice styles and preferences of ASCRS members 2003 survey. J Cataract Refract Surg. 2004;30:892-900.

11. Jusufbegovic D, Mugavin MO, Schaal S. Evolution of controlling diabetic retinopathy: changing trends in the management of diabetic macular edema at a single institution over the past decade. Retina. 2015;35: 929-934.

12. Desai MA, Gedde SJ, Feuer WJ, et al. Practice preferences for glaucoma surgery: a survey of the American Glaucoma Society in 2008. Ophthalmic Surg Lasers Imaging. 2011;42:202-208.

13. Ramulu PY, Corcoran KJ, Corcoran SL, et al. Utilization of various glaucoma surgeries and procedures in Medicare beneficiaries from 1995 to 2004. Ophthalmology. 2007;114:2265-2270.

14. Chadha N, Liu J, Teng CC. Resident and fellow glaucoma surgical experience following the tube versus trabeculectomy study. Ophthalmology. 2015;122:1953-1954.

15. ACGME case log statistical reports for ophthalmology residents 2009-2015. Available from: http://www.acgme.org/acgmeweb/ tabid/274/DataCollectionSystems/ResidentCaseLogSystem/CaseLogsStatisticalReports.aspx. Accessed January 28, 2016.

16. Scott AB, Magoon EH, McNeer KW, et al. Botulinum treatment of childhood strabismus. Ophthalmology. 1990;97:1434-1438.
Clinical Ophthalmology

\section{Publish your work in this journal}

Clinical Ophthalmology is an international, peer-reviewed journal covering all subspecialties within ophthalmology. Key topics include: Optometry; Visual science; Pharmacology and drug therapy in eye diseases; Basic Sciences; Primary and Secondary eye care; Patient Safety and Quality of Care Improvements. This journal is indexed on

\section{Dovepress}

PubMed Central and CAS, and is the official journal of The Society of Clinical Ophthalmology (SCO). The manuscript management system is completely online and includes a very quick and fair peer-review system, which is all easy to use. Visit http://www.dovepress.com/ testimonials.php to read real quotes from published authors. 